This is the accepted version of

Horváth, J., Gaál, Z. A., \& Volosin, M. (2017). Sound offset-related brain potentials show retained sensory processing, but increased cognitive control activity in older adults. Neurobiology of Aging, 57, 232-246. https://doi.org/10.1016/j.neurobiolaging.2017.05.026

(c) 2017. This manuscript version is made available under the CC-BY-NC-ND 4.0 license http://creativecommons.org/licenses/by-nc-nd/4.0/

\title{
Sound offset-related brain potentials show retained sensory processing, but increased cognitive control activity in older adults
}

\author{
János Horváth ${ }^{1}, Z_{\text {Zsófia Anna Gaál }}{ }^{1}$, Márta Volosin ${ }^{1,2,3}$ \\ ${ }^{1}$ Institute of Cognitive Neuroscience and Psychology, Research Centre for Natural Sciences, \\ Hungarian Academy of Sciences, Budapest, Hungary \\ ${ }^{2}$ Eötvös Loránd University, Faculty of Education and Psychology, Hungary \\ ${ }^{3}$ University of Leipzig, Cognitive and Biological Psychology, Germany
}

Address correspondence to:

János Horváth

Institute of Cognitive Neuroscience and Psychology, RCNS, HAS

P.O.B. 286,

H-1519

Budapest

HUNGARY

Phone: +36 13826800

E-mail: horvath.janos@ttk.mta.hu 


\begin{abstract}
It has been hypothesized that age-related hearing loss is caused not only by peripheral, but also central changes in the auditory system. Many studies utilized event-related potentials (ERPs) elicited by sound onsets to characterize age-related differences in central auditory processing. Age-related ERP enhancements in such studies have often been interpreted in terms of elevated sensitivity to auditory stimulation. Such ERPs, however, comprise various components reflecting different aspects of auditory and task-related processing. The composition of the waveforms may considerably differ for ERPs elicited by other auditory events. In the present study ERPs elicited by tone-offsets were used to characterize processing differences between younger and older adults in a short-go, tone-duration discrimination paradigm. Whereas the onset-related auditory ERP was enhanced in the older adult group, no age-related differences were found in the offset-related auditory ERPs observable at temporal electrodes. In older adults, however, offset-related processing was dominated by an N2 that could reflect enhanced cognitive control activities. Because N2 was present regardless discrimination difficulty, younger adults may have framed the task as offset-detection, whereas older adults represented the task as "genuine" discrimination.
\end{abstract}

Keywords: aging, hearing, event-related potentials, cognitive control, T-complex, N2 


\section{Introduction}

Human sensory systems change over the lifespan. Developmental and age-related changes affect the transduction of physical effects, as well as the processing of the resulting sensory signals. Maintaining optimal behavior despite these changes may require adaptation in non-peripheral, or even in non-sensory systems (Peelle \& Wingfield, 2016). But because these systems are also affected by aging (Wayne, \& Johnsrude, 2015), characterizing agerelated changes in the interaction of peripheral and central, as well as sensory and non-sensory processing is not trivial. The deterioration of hearing with age (presbycusis, for a review see Gates, \& Mills, 2005) has numerous manifestations. Beside the most frequently measured increase in pure tone detection thresholds, various paradigms show reduced temporal resolution (Humes, et al., 2010), and difficulties in speech understanding (see e.g., Humes, 1996; Marshall, 1981). Although some problems may be directly related to hearing threshold increases at higher frequencies (e.g., loss of discrimination ability for phonemes with high frequency components), certain aspects of hearing may be impacted even in the absence of such a threshold change (Bharadwaj, et al., 2015). This suggests that the causes of presbycusis are manifold, and different paradigms may reflect different (combinations of) hearing function changes. Although recent research suggests that some of these changes can be largely attributed to various peripheral causes (e.g., loss of outer hair cells, or cochlear neuropathy; Plack et al., 2016), it has also been suggested that certain aspects of age-related hearing problems are caused by changes in central auditory processing (Humes, et al., 2012). The goal of the present study was to characterize age-related differences in central auditory and non-auditory processing reflected by event-related potentials (ERPs) elicited by toneoffsets in a duration discrimination task.

Sound onsets elicit an ERP waveform comprising various deflections at various latencies (see e.g., Picton, et al., 1974). The late part of this waveform comprises the P1, N1 
and $\mathrm{P} 2$ deflections (peaking respectively at around 50, 100, and $170 \mathrm{~ms}$ ). Age-related differences in these ERPs have been investigated in numerous experiments, which mostly showed that these ERPs were enhanced in older adults (or no significant differences were present). Age-related enhancements of P1 or its enhancements magnetic counterpart were found, for example, by Alain et al. (2012), Bertoli et al. (2005), Fabiani et al. (2006), Kovacevic et al. (2005), Pekkonen et al. (1995), Pfefferbaum et al. (1979), and Smith et al. (1980). An N1 amplitude increase with growing age was found among others by Amenedo and Díaz (1998), Anderer et al. (1996, 1998), Ford and Pfefferbaum (1991), and Pfefferbaum et al. (1984); but Goodin et al. (1978) observed age-related reduction of the N1-P2 amplitude (measured from peak-to-peak). Age-related P2-amplitude increases were found, for example, by Ford and Pfefferbaum (1991), Pfefferbaum et al., (1984); but Czigler et al. (1992), and Ross and Tremblay (2009), found lower P2 amplitudes in older than in younger participants.

Although some of these ERPs reflect the physical characteristics of the stimulation (e.g., louder sounds elicit larger, and earlier N1s, see Näätänen and Picton, 1987), they are also influenced by cognitive factors, for example by the attentional orientation of participants (Hillyard et al., 1973): When participants perform tasks related to one stimulus channel (e.g., a given ear: Woldorff and Hillyard, 1991) N1 amplitude is enhanced for the sounds presented in the given channel. That is, these ERPs reflect the interaction of sensory processing and its top-down modulation. Building on this, if an experiment administers equivalent auditory stimulation in two conditions, then between-condition ERP differences would reflect differences in top-down modulation. Indeed, age-related amplitude enhancements have been generally interpreted as signs of a general age-related increase in sensitivity to auditory stimuli. This may reflect a declined ability to inhibit sensory processing (Alain and Woods, 1999; Chao and Knight, 1997; Stothart and Kazanina, 2016), or more generally, to inhibit the processing of irrelevant pieces of information (Gazzaley et al., 2005; Hasher et al., 1999; 
Hasher and Sacks, 1988). Such a sensitivity increase may, however, not only reflect a decline, but also an adaptation to a peripheral deficit: some studies presenting physically identical sounds to participants with peripheral hearing loss found enhanced auditory ERPs in comparison to participants with normal hearing despite elevated pure tone thresholds (Alain et al., 2014; Harkrider et al., 2006; Morita et al., 2003).

Although the interpretations above seem straightforward, there are a number of inconsistencies. Whereas the sign of the age-related effects on the onset-related waveforms (i.e. amplitude enhancement with growing age) is consistent for P1 across studies, for N1, and especially P2, consistency decreases, with more counter-examples showing reductions with growing age. It is also important to note that the ERP waveform elicited by other transient events, for example by short gaps in continuous tones shows the opposite pattern as a function of age: gap-related N1 and P2 are markedly reduced in older adults in comparison to younger adults (Harris et al., 2012; Volosin et al., 2017).

Furthermore, the reported onset-related ERP enhancements do not seem to follow a pattern reflecting a single cause: in many studies an age-related enhancement was found for one or two of the waveforms, but not for the other(s). Although these waveforms certainly have generators in auditory areas of the temporal cortex (see e.g., Crowley and Colrain, 2004; Godey et al., 2001; Halgren et al., 1995; Liegeois-Chauvel et al., 1994; Lütkenhöner and Steinsträter, 1998; McEvoy et al., 1994; Nakagawa et al., 2014; Scherg et al., 1989), they nonetheless comprise different components, which may account for the inconsistencies described above. The N1 waveform has at least three sub-components (Näätänen and Picton, 1987). Two of these originate from auditory areas: The supra-temporal component, which exhibits a frontally negative peak and a positive peak at electrodes under the Sylvian-fissure when the EEG is recorded with a nose-reference, is well modeled by a tangential equivalent dipole placed in the supra-temporal cortex (Vaughan and Ritter, 1970). The T-complex 
(Wolpaw and Penry, 1975) is mainly observable at temporal sites, with a field well-described by radially oriented equivalent dipolar sources at the lateral sides of the temporal cortices, which may reflect activity in secondary auditory areas (Scherg and Von Cramon, 1986; Ponton et al., 2002). It has been suggested that P2 comprises at least two components as well (Verkindt et al., 1994). Further ERP components overlapping the N1 and P2 can be found in different stimulation and task arrangements (Näätänen and Picton, 1987). In tasks requiring sound-based decisions, the deflection descriptively labeled as N1 may actually receive contributions from the processing negativity (PN, Näätänen et al., 1978; or negative difference - Nd, see Hansen and Hillyard, 1980) or N2 (Horváth, 2016) components. Whereas PN probably reflects processing related to the matching of the incoming sound to a voluntarily maintained auditory template, an attentional trace (Näätänen, 1982, 1990), N2 may reflect the evaluation of the stimulus in terms of the given task (Ritter et al., 1979). The positive waveform descriptively labeled as P2 may actually receive contributions from an overlapping PN or N2 (Czigler et al., 1992), which reduce its amplitude (or even make it unobservable, if the task-related N2 is much larger than the P2, see e.g., Experiment 3 in Horváth, 2016); or it can be enhanced by a P3a, which is elicited by unpredictably occurring stimuli (Friedman et al., 2001). That is, sounds presented in different experimental paradigms may have different processing demands, which are also reflected in the component-structure underlying the ERP waveforms. Consequently, age-related ERP differences may have markedly different causes across paradigms.

The present study is based on the idea that different types of stimulations may require different patterns of processing, which may also be reflected in the composition of the auditory ERPs. Alain et al. (1997), for example, showed that N1 subcomponents indexed processes with different temporal integration times, which was reflected in their amplitudes when tone durations were varied in the 8-72 ms range. Although studies on age-related 
changes in auditory processing mostly used sound onsets to elicit P1, N1 and P2, auditory ERPs can also be elicited by other types of auditory events. In the present study, instead of focusing on ERPs elicited by sound onsets, we focused on ERPs elicited by sound offsets.

The processing of sound onsets and offsets includes common, as well as event-specific processes. Neural responses to offsets have been identified in animal studies at all stages of the auditory pathway from the cochlear nucleus (e.g., Suga, 1964), to the auditory thalamus (He, 2001, 2002) and the auditory cortex (e.g., Fishman and Steinschneider, 2009; Qin et al., 2007; Recanzone, 2000; for a recent overview, see Ramamurthy and Recanzone, 2017). It has also been shown that onset and offset responses in the auditory cortex - even if produced by the same neurons - are likely driven by separate sets of synapses (Scholl et al., 2010; O’Connell et al., 2011).

ERP waveforms elicited by onsets and offsets are largely similar (Davis and Zerlin, 1966; Hillyard and Picton, 1978; Onishi and Davis, 1968). The magnetic reflections of these ERPs have overlapping generator structures according to some studies (Hari et al., 1987; Pantev et al., 1996; Yamashiro et al., 2011), whereas others (Noda et al., 1998) suggest the involvement of separate structures. The onset-related auditory ERP signal features a positivity at around $100 \mathrm{~ms}$ post-onset at temporal electrodes (the Ta sub-component of the T-complex), which is followed by a negativity (the Tb, at around $150 \mathrm{~ms}$, Wolpaw and Penry, 1975), while a negativity is observable at the fronto-central electrodes at around $100 \mathrm{~ms}$ (reflecting - at least in part - the supra-temporal N1 subcomponent). Whereas onset-related auditory ERPs are readily observable in most paradigms, most previous studies suggested that offset-related ERPs are mainly observable when tone durations are long (i.e. longer than $1 \mathrm{~s}$, Näätänen and Picton, 1987). A recent set of studies, however, demonstrated that attended sound offsets elicit a positive-negative-positive waveform with similar temporal structure as the onset-related P1N1-P2 ERP (Horváth, 2014). Although the between-deflection intervals were very similar to 
those observable in a typical onset-related waveform, the waveform itself was uniformly delayed by about $50 \mathrm{~ms}$ (i.e., the $\mathrm{P} 1$ peaked at about $100 \mathrm{~ms}$, and the $\mathrm{N} 1$ at about $150 \mathrm{~ms}$ after the start of the offset transient). Interestingly, the waveform was most prominently observable at temporal sites (Horváth, 2016). Because of its topographical distribution and timing, it was suggested that the offset-related waveform may be analogous to the T-complex rather than to the typical onset-related waveform, in which the fronto-central negativity at $100 \mathrm{~ms}$ is the most pronounced. The experiments by Horváth (2016) also revealed that the negative part of the offset-related waveform was composed of two components: one reflecting sensory offsetprocessing $(\mathrm{N} 1)$, and one reflecting the processing of the offsets in task-related terms (N2). Whereas N1 was most clearly distinguishable at temporal sites, it was dominated by an N2 at central electrodes (forming a monolithic N1/N2 waveform) when the stimulation was more complex (i.e. pitch or stimulus presentation rate varied during the experiment). In a study investigating age-related differences in distraction, a similar offset-related P1-N1-P2 waveform was found, which seemed to be delayed by about $80 \mathrm{~ms}$ in older adults (Horváth et al., 2009). These results show that offset-related ERPs may allow different insights on agerelated differences in sound processing from that offered by onset-related ERPs. The present study was a targeted investigation of the results by Horváth et. al. (2009), which omitted the distraction aspect of their paradigm, used multiple durations, and administered the task to larger younger and older adult groups than the previous studies (Horváth et al., 2009, and Horváth, 2016).

Based on Horváth et al. (2009), we hypothesized that offset-related processing will be delayed in the older adult group, which will be reflected by the delayed elicitation of the offset-related ERP waveform. To separate N1 and N2 contributions, ERPs from trials with faster and slower-than-median responses were separately averaged. Because N2 latency is 
known to covary with response latency, we hypothesized that this would allow the separation of the two components.

\section{Materials \& Methods}

\subsection{Participants}

Participants reported no history of neurological disorders, and gave written informed consent after the experimental procedures were explained to them. 21 younger adult volunteers, recruited by a student part-time job-agency, and 22 older adult volunteers, recruited from the participant database of the department participated in the experiment for monetary compensation. All of them were right-handed women. Data from two older adult participants were not used in the analyses because of extensive eye-movements resulting in the loss of more than $80 \%$ of the EEG epochs during artifact-rejection (see below). The remaining participants were aged 20-24 years (mean 22, standard deviation 2) in the younger, and 61-73 years (mean 66, standard deviation 3) in the older adult group. The mean IQ scores (measured by the Hungarian version of the Wechsler Adult Intelligence Scale, Fourth Edition, WAIS-IV completed in a separate session) were higher than average in both groups, as shown by a two-tailed $\mathrm{t}$-test against $100:(\mathrm{t}[19]=6.346, \mathrm{p}<.001$ for the older, and $\mathrm{t}[20]=2.680, \mathrm{p}=$ .014 in the younger adult group); the mean IQ scores were also higher in the older than in the younger adult group (see Table 1). The participants had no more than $10 \mathrm{~dB}$ hearing threshold difference between the two ears at 500, 1000, and $2000 \mathrm{~Hz}$ (measured by an SA-6 audiometer, Mediroll, Debrecen, Hungary). The mean thresholds were higher in the older than in the younger adult group at all measured frequencies (see Table 1).

\subsection{Stimuli and procedures}

The stimulation was largely similar to that used previously by Horváth $(2014,2016)$. Participants were sitting in an armchair in a sound-proofed room. Tones comprising three 
harmonics (700, 1400 and $2100 \mathrm{~Hz}$ sinusoids with relative amplitudes of $0,-3$, and $-6 \mathrm{~dB}$ ) were presented through headphones (HD-600, Sennheiser, Wedemark, Germany). The experiment consisted of three conditions. In each condition, pseudo-randomized sequences of short and long tones were presented. The duration of the long tone was $750 \mathrm{~ms}$ in each condition, whereas the short tone was either 150,300, or $450 \mathrm{~ms}$ long in the given condition. All tones included 2.5-2.5 ms linear rise and fall times. The intensity of the tones was individually adjusted to $50 \mathrm{~dB}$ above hearing threshold level using a continuous version of the tone presented in the experiment. The conditions were presented in random order for each participant. Each condition was divided into 5 stimulation sequences comprising 87 short- and 87 long tones presented in a pseudo-randomized order with an onset-to-onset interval of 1300 ms. The first four stimuli of each sequence comprised a "short-long-short-long" microsequence to demonstrate the duration-difference to the participants, who were informed of this introduction sequence. Participants were instructed to press a button held in their dominant (right) hand as fast as possible when the short tone was presented, while maintaining a low false alarm rate, but not to respond to long tones. They also had to keep their gaze on a fixation puppet placed in front of them to minimize eye-movements. Consecutive stimulation sequences were separated by short breaks as needed, with longer breaks between conditions. Before and after the electrode-cap was mounted, participants practiced the task in pseudorandomized sequences consisting of 42 short (450 ms), and 42 long (750 ms) tones. At the end of each sequence, feedback on the correct response rate and reaction time distribution was provided and discussed. Due to a software problem, tone presentation randomly, occasionally stopped for 5 seconds in some of the blocks (on average, $15 \%$ of the blocks were affected by such an irregularity). Responses to the three stimuli following such hang-ups, as well as responses to the first four tones of each block were excluded from the analyses.

\subsection{Behavioral data analysis}


In each condition, trials were categorized as hits, false alarms, correct rejections and misses based on the presence or absence of responses in the 50-850 ms interval following the timepoints of potential short-tone offsets. Overall, this selection procedure resulted in the inclusion of $98.1 \%$ of the trials in the analyses. d' sensitivity scores (according to Signal Detection Theory, for a summary, see Macmillan and Creelman, 2005) were calculated for each condition and each participant. Hit rates of 1 and false alarm rates of zero were adjusted to $1-(1 /(2 \mathrm{~N}))$ and $1 /(2 \mathrm{~N})$, respectively (where $\mathrm{N}$ is the number of stimuli requiring a response, see Macmillan and Creelman, 2005) to avoid infinite values in the calculations. To compensate for the potentially skewed individual reaction time distributions, participants' reaction times were calculated as the median of their reaction times for hits. d' scores and reaction times were analyzed in two-way mixed analyses of variance (ANOVA) with group as a between-group factor and condition as a three-level, repeated measures factor. GreenhouseGeisser-correction was applied as appropriate (epsilon values are reported with the uncorrected degrees of freedom). Generalized eta-squared effect sizes (Olejnik and Algina, 2003; Bakeman, 2005) are reported.

\subsection{EEG-recording and analysis}

The electroencephalogram (EEG) was recorded with nose reference with a sampling rate of $1000 \mathrm{~Hz}$ (200 Hz on-line low-pass filter, Synamp 2, Compumedics, Victoria, Australia) by $61 \mathrm{Ag} / \mathrm{AgCl}$ electrodes mounted on an elastic cap (EASYCAP, Herrsching, Germany) using a 10\% arrangement (Nuwer et al., 1998). Two additional electrodes were placed at the mastoids. A bipolar setup of electrodes placed close to the outer canthi of the two eyes was used to record the horizontal electrooculogram (EOG). Vertical EOG was calculated off-line by subtracting the signal of an electrode placed under the right eye from the signal measured at Fp2. The EEG was off-line $20 \mathrm{~Hz}$ low-pass filtered (Kaiser-windowed sinc finite impulse response filter, beta of 4.53, 1465 coefficients, transition bandwidth $2 \mathrm{~Hz}$, 
stopband attenuation at least $50 \mathrm{~dB}$ ). $1300 \mathrm{~ms}$ long epochs including a $200 \mathrm{~ms}$ long pre-tone interval corresponding to short and long tones in each condition were extracted from the filtered EEG. Epochs with a signal range exceeding $100 \mu \mathrm{V}$ on any channel were discarded. The remaining epochs were averaged for each participant. The average signal in the pre-tone interval was used as a reference (baseline) in the amplitude calculations.

First, ERP activity preceding tone onsets was characterized. As in previous studies using fixed inter-onset-intervals in duration- or direction discrimination tasks (e.g., Berti and Schröger, 2001; Horváth, 2014, 2016; Volosin and Horváth, 2014), the stimulus onset was preceded by a negative ERP trend. The steepness of this pre-stimulus trend was calculated as the difference of the average amplitudes measured at in the $200-150 \mathrm{~ms}$ and the $50-0 \mathrm{~ms}$ intervals preceding tone onsets in each condition. Steepness values were submitted to a mixed Group $\times$ Condition (repeated measures, 150, 300, or 450 ms vs. 750 ms) ANOVA.

Because onset-related auditory P1 and N1 waveforms were superimposed on the ERP trend described above (which differed significantly between conditions), onset-related P1 and $\mathrm{N} 1$ amplitudes were characterized together by the differences in their amplitudes (i.e. peak-topeak amplitudes). P1-N1 amplitudes were calculated as the differences of the average signals in the $20 \mathrm{~ms}$ long window centered at the P1 and N1 peaks, and were submitted to a Group $\times$ Condition mixed ANOVA.

To assess offset-related ERPs in each condition, short-minus-long ERP difference waveforms were calculated. P1 and N1/N2 peaks were visually identified in the group average difference waveforms. Individual P1 and N1/N2 amplitudes were calculated as the average signals in $20 \mathrm{~ms}$ long intervals centered at the respective group-average peak latencies (measured at $\mathrm{Cz}$ ) in each group. These were submitted to mixed Group $\times$ Condition $\times$ Electrode (T7, Cz, T8) ANOVAs. These electrodes were pre-selected because previous 
experiments (Horváth, 2016) suggested that N2 and P3b may overlap the offset-related P1 and $\mathrm{N} 1$ at temporal electrodes to a lesser degree than at central ones. Conversely, it was expectable that potential ERP amplitude effects stemming from the overlap of these ERPs will be more pronounced at the central electrode, and will be manifested by interaction effect(s) involving the Electrode factor.

To assess whether between-group differences were present in the latencies of the ERPs observable in the difference waveforms, their peak latencies measured at $\mathrm{Cz}$ were analyzed by applying the jackknife procedure as described by Kiesel, et al., (2008) in mixed Group $\times$ Condition (150, 300, or $450 \mathrm{~ms}$ vs. $750 \mathrm{~ms})$ ANOVAs. For these calculations the jackknifeadjusted F-values (when appropriate, the size of the larger group was used), GreenhouseGeisser epsilons if applicable, unadjusted degrees of freedom, and adjusted p-values are reported.

To assess whether the latency of the offset-related waveforms varied with reaction time, which may indicate that reaction-time sensitive components, like the N2 or P3b contribute to the waveforms, short tones followed by correct responses were sorted according to reaction time, and ERP epochs corresponding to short tones with faster-than-, and slowerthan-median reaction times were averaged separately (see Horváth, 2016). Using the jackknife procedure described by Kiesel et al. (2008), the offset-related P1 (measured at T7), N1/N2 (measured at $\mathrm{Cz}$ ), and $\mathrm{P} 3 \mathrm{~b}$ (measured at $\mathrm{Pz}$ ) latencies were submitted to mixed Group $\times$ Partition (faster-, or slower-than-median) $\times$ Condition $(150,300$, or $450 \mathrm{~ms}$ vs. $750 \mathrm{~ms})$ ANOVAs. Note that in these analyses, the offset-related waveform was identified in the short tone-related ERP (because long tones did not require a response). For two jackknife means in the younger adult group, no local N1 maxima, only a shoulder could be found at Cz; in these cases, the latency at which the temporal derivative of the $\mathrm{Cz}$ signal (the difference of consecutive signal samples) was closest to zero was used. 


\section{Results}

\subsection{Behavioral data}

Group-average reaction times and d' sensitivity scores are presented in Figure 1. The ANOVA of the reaction times (in reference to short tone-offset) showed a significant Group main effect: $F(1,39)=16.164, \eta_{\mathrm{G}}{ }^{2}=0.251, \mathrm{p}<0.001$, showing that older adults responded slower than younger adults; and a Condition main effect: $\mathrm{F}(2,78)=21.877, \varepsilon=0.701, \eta_{\mathrm{G}}{ }^{2}=$ 0.097, $\mathrm{p}<0.001$. Following-up the Condition main effect, pair-wise t-tests (with pooled groups) showed that reaction times significantly differed between all three conditions ( $\mathrm{t}[40]-$ scores $>2.625$; p-values $<0.013$ ): they were the fastest in the $300 \mathrm{vs} .750 \mathrm{~ms}$, and slowest in the 450 vs. $750 \mathrm{~ms}$ condition.

The ANOVA of the d' sensitivity scores showed a significant Condition main effect: $\mathrm{F}(2,78)=54.893, \varepsilon=0.907, \eta_{\mathrm{G}}{ }^{2}=0.275, \mathrm{p}<0.001 ;$ and a significant Group $\times$ Condition interaction: $\mathrm{F}(2,78)=3.277, \varepsilon=0.907, \eta_{\mathrm{G}}{ }^{2}=0.022, \mathrm{p}=0.048$. In both groups pair-wise t-tests showed that d's were significantly lower in the $450 \mathrm{vs} .750 \mathrm{~ms}$ condition than in the other two $(\mathrm{t}[20]>4.258$ in the younger adult group for both comparisons, $\mathrm{t}[19]>6.985$ in the older adult group for both comparisons, p-values $<0.001$ in both groups). Following-up the interaction, pair-wise, two-sample, Welch t-tests showed that the d' difference between the 150 vs. $750 \mathrm{~ms}$ and the 450 vs. $750 \mathrm{~ms}$ conditions was larger in the older than in the younger adult group $(\mathrm{t}[38.662]=2.197 ; \mathrm{p}=0.034$; none of the other comparisons showed significant differences).

\subsection{ERPs}

The group-average ERPs and the short-minus-long difference waveforms elicited in the younger and older adult groups are presented in Figures 2, 3 and 4. As in previous studies (e.g., Berti and Schröger, 2001; Horváth, 2014, 2016; Volosin and Horváth, 2014), tone 
onsets were preceded by a negative-going ERP trend, suggesting that participants exploited the constant SOA to prepare for the tones. Tone onsets elicited the succession of P1, N1 and P2 waveforms, which were superimposed on the negative trend. P2 was followed by a sustained negativity, lasting approximately till the time-point of the potential short tone offset in each condition. This was followed by a parietal positivity, identified as a P3b.

\subsubsection{ERPs-pre-stimulus interval}

The steepness of the negative trend was maximal at centro-parietal sites in the group average waveforms (with maxima at $\mathrm{CP} 3, \mathrm{CP} 4$, and $\mathrm{PO} 4$ in the two groups and three conditions). To measure steepness values, $\mathrm{CPz}$ was selected as the electrode closest to the maxima described above. The steepness values were submitted to a Group $\times$ Condition ANOVA, which showed a significant Condition main effect only: $\mathrm{F}(2,78)=4.667, \varepsilon=0.932$, $\eta_{\mathrm{G}}{ }^{2}=0.048, \mathrm{p}=0.014$. Following-up the Condition main effect, pair-wise t-tests (with pooled groups) showed that the negative trend was significantly less steep in the $450 \mathrm{vs} .750 \mathrm{~ms}$ than in the 150 vs. $750 \mathrm{~ms}$ condition $(\mathrm{t}[40]=2.712 ; \mathrm{p}=0.001)$.

\subsubsection{ERPs - onset-related waveforms}

The onset-related P1 peaked in the group average waveforms mainly at frontal, frontocentral sites (maxima at FC3, FC6, AF8, Fpz, AF4), with a mean latency of $48 \mathrm{~ms}$ (42-51 ms latency range) in the two groups and three conditions (because there were no physical differences between short and long tones at the onset, these were pooled). N1 peaked at fronto-central, central sites (maxima at $\mathrm{FCz}, \mathrm{Cz}$, and $\mathrm{CPz}$ ), with a mean latency of $93 \mathrm{~ms}$ (9195 ms latency range) in the two groups and three conditions. Therefore the P1-N1 amplitudes were measured as the difference of the average signal at $\mathrm{FCz}$ (as the electrode closest to the maxima described above) in the $38-58 \mathrm{~ms}$ and the $83-103 \mathrm{~ms}$ intervals (peak -to-peak). The P1-N1 difference amplitudes were submitted to a Group $\times$ Condition ANOVA, which showed 
a significant Group main effect: $F(1,39)=24.055, \eta_{\mathrm{G}}{ }^{2}=0.362, \mathrm{p}<0.001$, showing that the amplitudes were higher in the older adult group; and a significant Condition main effect: $\mathrm{F}(2,78)=10.280, \varepsilon=0.942, \eta_{\mathrm{G}}{ }^{2}=0.020, \mathrm{p}<0.001$. Following-up the Condition main effect, pair-wise t-tests (with pooled groups) showed significant differences between all conditions $(\mathrm{t}[40]$-scores $>2.105 ; \mathrm{p}$-values $<0.042)$ : the amplitude was highest in the $150 \mathrm{vs} .750 \mathrm{~ms}$, and lowest in the 450 vs. $750 \mathrm{~ms}$ condition.

\subsubsection{ERPs-offset-related activity}

As in previous studies, offset-related ERP activity was characterized by a positivenegative transient waveform most readily observable at the temporal electrodes (marked by black arrows at T8 in Fig. 2 and 3), superimposed on the slow decay of the sustained ERP. As in previous studies, long tone offsets were followed by similar offset-related transient waveforms (marked by gray arrows at T8 in Fig. 2 and 3).

The group-average short-minus-long difference waveforms are contrasted in Figure 4. Previous studies showed that the offset-related waveforms are likely to be overlapped by the N2 and P3b. Based on previous experiments (Horváth, 2016) electrodes with potentially maximal (Cz) and minimal (T7 and T8) N1-N2 overlap were used in these analyses, whereas P3b was characterized by the amplitude measured at Pz. The offset-related group-average P1 and N1/N2 peak latencies measured at $\mathrm{Cz}$, and P3b peak latencies measured at Pz in the shortminus-long difference waveforms of the three conditions are presented in Table 2. The topographical distributions of the ERPs (average amplitudes measured in 20 ms windows centered at these time points) are shown in Figure 5.

The Group $\times$ Condition $(150,300$, or $450 \mathrm{~ms}$ vs. $750 \mathrm{~ms}) \times$ Electrode $(\mathrm{T} 7, \mathrm{Cz}, \mathrm{T} 8)$ ANOVA of the offset-related P1 amplitudes (measured in $20 \mathrm{~ms}$ windows centered at the peak amplitudes at $\mathrm{Cz}$ in the group-average short-minus-long difference waveforms, Table 2) 
showed a significant Condition main effect: $\mathrm{F}(2,78)=5.705, \varepsilon=0.853, \eta_{\mathrm{G}}{ }^{2}=0.045, \mathrm{p}=$ 0.007; a significant Electrode main effect: $\mathrm{F}(2,78)=30.145, \varepsilon=0.855, \eta_{\mathrm{G}}{ }^{2}=0.113, \mathrm{p}<0.001$; and a significant Condition $\times$ Electrode interaction: $\mathrm{F}(4,156)=14.148, \varepsilon=0.813, \eta_{\mathrm{G}}{ }^{2}=0.038$, $\mathrm{p}<0.001$. The interaction was resolved by separate one-way Condition ANOVAs (with participant groups pooled), which showed a significant effect only at $\mathrm{Cz}$ : $\mathrm{F}(2,80)=15.486, \varepsilon$ $=0.877, \eta_{\mathrm{G}}{ }^{2}=0.139, \mathrm{p}<0.001$; showing that the amplitude was the lowest in the $150 \mathrm{vs} .750$ ms, and highest in the 450 vs. $750 \mathrm{~ms}$ condition (as indicated by pair-wise t-tests: $\mathrm{t}[40]$-scores $>2.067$; $\mathrm{p}$-values $<0.05)$. This indicates that $\mathrm{P} 1$ received a positive contribution at the central sites, which increased with the duration of the short tone across conditions.

The Group $\times$ Condition $\times$ Electrode ANOVA of the offset-related N1/N2 amplitudes showed a significant Condition main effect: $\mathrm{F}(2,78)=22.220, \varepsilon=0.940, \eta_{\mathrm{G}}{ }^{2}=0.072, \mathrm{p}<$ 0.001; a significant Group $\times$ Electrode interaction: $\mathrm{F}(2,78)=8.487, \varepsilon=0.741, \eta_{\mathrm{G}}{ }^{2}=0.041, \mathrm{p}$ $=0.002$; a significant Condition $\times$ Electrode interaction: $\mathrm{F}(4,156)=4.850, \varepsilon=0.786, \eta_{\mathrm{G}}{ }^{2}=$ $0.005, \mathrm{p}=0.003$; and a significant Group $\times$ Condition $\times$ Electrode interaction: $\mathrm{F}(4,156)=$ $2.837, \varepsilon=0.786, \eta_{\mathrm{G}}^{2}=0.003, \mathrm{p}=0.039$. Following-up the three-way interaction, separate Group $\times$ Condition ANOVAs were conducted for the three electrode levels. For the amplitudes at $\mathrm{Cz}$, a significant Group main effect: $\mathrm{F}(1,39)=4.755, \eta_{\mathrm{G}}{ }^{2}=0.096, \mathrm{p}=0.03$, showing more negative amplitudes in the older than in the younger adult group; and a significant Condition main effect: $\mathrm{F}(2,78)=22.425, \varepsilon=0.946, \eta_{\mathrm{G}}{ }^{2}=0.067, \mathrm{p}<0.001$ was found. For the amplitudes at T7 and T8, only significant Condition main effects were found $\left(\mathrm{F}[2,78]=20.364, \varepsilon=0.850, \eta_{\mathrm{G}}^{2}=0.123, \mathrm{p}<0.001 ; \mathrm{F}[2,78]=10.877, \varepsilon=0.896, \eta_{\mathrm{G}}{ }^{2}=0.066\right.$, $\mathrm{p}<0.001$, for $\mathrm{T} 7$ and $\mathrm{T} 8$, respectively). For all three electrodes, the Condition main effect was caused by higher (more negative amplitudes) in the 150 and $300 \mathrm{~ms}$ vs. $750 \mathrm{~ms}$ conditions than in the 450 vs. $750 \mathrm{~ms}$ condition (as indicated by pair-wise t-tests: $\mathrm{t}[40]$-scores $>3.046$; p-values $<0.008$ ). Taken together, this indicates that N1 was enhanced for the short 
duration conditions in comparison to the 450 vs. $750 \mathrm{~ms}$ condition; and that the monolithic N1/N2 waveform received a substantial central ERP contribution (presumably an N2) in the older adult group in comparison to the younger adults (Figure 5, middle rows).

The Group $\times$ Condition ANOVA of the offset-related P3b amplitudes (measured at Pz) showed a significant Group main effect: $\mathrm{F}(1,39)=6.162, \eta_{\mathrm{G}}{ }^{2}=0.121, \mathrm{p}=0.017$, showing more positive amplitudes in the younger adult group; and a significant Condition main effect: $\mathrm{F}(2,78)=6.381, \varepsilon=0.993, \eta_{\mathrm{G}}{ }^{2}=0.020, \mathrm{p}=0.003$. The Condition main effect was followedup by pair-wise t-tests (with pooled groups), which showed that the amplitude of the $150 \mathrm{vs}$. $750 \mathrm{~ms}$ condition was significantly higher (more positive) than in the other two conditions $(\mathrm{t}[40]$-scores $>2.093$, p-values $<0.043)$.

The Group $\times$ Condition $(150,300$, or $450 \mathrm{~ms}$ vs. $750 \mathrm{~ms})$ ANOVAs of the jackknife peak latencies (measured at $\mathrm{Cz}$ in the short-minus-long difference waveforms; Figure 6) as described by Kiesel et al. (2008) showed no significant effects for P1 or P3b. For N1/N2, however, a significant Group main effect was present: $\mathrm{F}(1,39)=18.814, \eta_{\mathrm{G}}{ }^{2}=0.990, \mathrm{p}<$ 0.001 , indicating longer peak latency in the older adult group. This latency shift may also reflect a substantial N2 contribution in the older adult group.

\subsubsection{ERPs -the latency of the offset-related ERP activity as the function of response speed}

The group-average ERPs elicited in short-tone trials with faster-, and slower-thanmedian responses are presented in Figure 7 and 8. Using the jackknife procedure described by Kiesel et al. (2008), the offset-related P1 (measured at T7), N1/N2 (measured at Cz), and P3b (measured at $\mathrm{Pz}$ ) latencies were submitted to mixed Group $\times$ Partition (faster-, or slower-thanmedian $) \times$ Condition $(150,300$, or $450 \mathrm{~ms}$ vs. $750 \mathrm{~ms})$ ANOVAs. The mean jackknife latencies are presented in Figure 9. For the P1, no significant effects were found. 
For the N1/N2 we found a significant Group main effect: $F(1,39)=97.827, \eta_{\mathrm{G}}{ }^{2}=$ 0.998, $\mathrm{p}<0.001$, showing later peaks in the older adult group; a significant Partition main effect: $F(1,39)=9.123, \eta_{\mathrm{G}}^{2}=0.985, \mathrm{p}=0.004$, showing later peaks for longer response times; and a significant Group $\times$ Partition interaction: $F(1,39)=10.276, \eta_{\mathrm{G}}{ }^{2}=0.949, \mathrm{p}=0.003$. Following up the interaction, a Welch two-sample t-test showed that the between-partition latency-difference was larger in the older, than in the younger adult group $(\mathrm{t}[29.069]=2.240$, $\mathrm{p}=0.033$ ). This result also reflects that in older adults the $\mathrm{N} 1 / \mathrm{N} 2$ receives a substantial $\mathrm{N} 2$ contribution.

As in previous experiments (Horváth, 2016), ERPs in trials with faster-than-median responses were characterized by a negative shift in the ERP preceding the N1/N2 peak (indicated by shaded between-curve areas in Figure 8). Because the bifurcation of the two ERPs may start already before tone onset, the magnitude of these partition-related differences may be biased by baselining; therefore, only a simple analysis was performed to confirm the presence of these shifts: The average ERP amplitudes at $\mathrm{Cz}$ in the $50 \mathrm{~ms}$ interval preceding offsets measured in the two partitions (as in Horváth, 2016) were submitted to paired Student's t-tests in each group and condition. All comparisons showed significantly more negative amplitudes in trials with faster-than-median responses (for the older adults: $t[19]-$ scores $>3.996$, p-values $<0.001$; for the younger adults: $\mathrm{t}[20]$-scores $>3.716, \mathrm{p}$-values $<$ $0.002)$.

For the P3b, a significant Group main effect was present: $F(1,39)=13.430, \eta_{\mathrm{G}}{ }^{2}=$ 0.978, $\mathrm{p}<0.001$, showing that P3b peaked later for older adults. A significant Partition main effect: $F(1,39)=21.399, \eta_{\mathrm{G}}{ }^{2}=0.992, \mathrm{p}<0.001$, indicated that $\mathrm{P} 3 \mathrm{~b}$ peaked later in trials with slower-than-median responses. Finally, a significant Condition main effect: $F(2,78)=4.076, \varepsilon$ $=0.709, \eta_{\mathrm{G}}{ }^{2}=0.976, \mathrm{p}=0.035$ was also found. Following-up the Condition main effect, pair- 
wise t-tests (with pooled groups) showed that P3b peaked significantly later in the $450 \mathrm{vs.} 750$ ms condition than in the other two conditions $(\mathrm{t}[40]$-scores $>2.225$, $\mathrm{p}$-values $<0.032)$.

\section{Discussion}

\subsection{Tone offset-related processing}

The present study investigated age-related differences in the processing of sound offsets in a duration discrimination paradigm presenting two tones in each condition. The long tone duration was $750 \mathrm{~ms}$ in all three conditions, whereas short tone duration was 150,300 , or $450 \mathrm{~ms}$. As in previous studies (Horváth, 2014, 2016), tone offsets were followed by a consistent positive-negative (P1-N1) waveform pattern most distinctly observable at the temporal leads in both groups, which, in combination with the fact that offset-related waveforms peaked about $50 \mathrm{~ms}$ later than the typical onset-related P1-N1 waveforms, may indicate that these offset-related waveforms reflected mainly the T-complex (Wolpaw and Penry, 1975) of the auditory ERP. Although the fronto-centrally peaking onset-related P1-N1 waveform was larger in the older adult group in correspondence with most previous studies (see Introduction), no significant between-group differences were found for the offset-related $\mathrm{P} 1$, or the temporally measured offset-related N1. These results are in agreement with the assumption that sound onset- and offset-related auditory ERPs reflect - at least in part different aspects of sensory processing, and that these aspects may be differentially affected by aging. In terms of the ERP components, one may speculate that whereas the P1 and the supra-temporal N1 subcomponents of the late auditory ERP (which are dominant in the ERP elicited by sound onsets) are affected by age, the T-complex (which seems to dominate the offset-related waveform) is not. The lack of an age-related difference in the offset-related auditory ERP is on a par with the results of Ross et al. (2009) showing no age-related differences in offset-related magnetic fields for short duration (34-76 ms) sounds. 
The offset-related N1 received a marked enhancement in the older adult group at central recording sites, which, combined with the increased latency of the negative waveform in the older adult group, suggests that N1 was overlapped by a centrally distributed $\mathrm{N} 2$ in the older adult group even at the shortest duration. This interpretation of the ERP pattern was also corroborated by the fact that separating slow- and fast-response trials significantly affected the latency of the central negative waveform only in the older adult group. This age-related difference in N2 elicitation may reflect a quantitative task-related processing difference. Because in discrimination tasks involving more similar stimuli higher N2s are elicited (Nieuwenhuis et al., 2004), the N2 difference may reflect that the discrimination task was more difficult for older than for younger adults. The behavioral data, however, does not seem to support this notion. Although older adults' responses to tone offsets were generally slower than those of younger adults, no age-related reaction time modulation was found, that is, between-group reaction time differences did not substantially change as a function of discrimination difficulty. An age-related discrimination performance loss in the d' sensitivity score was only present in the 450 vs. 700 ms condition. Because N2 was clearly present in the older adult group even in the condition with the shortest duration, it seems unlikely that the presence of $\mathrm{N} 2$ in older adults was caused by a task-difficulty difference.

Because N2 reflects cognitive control processes (Donkers and van Boxtel, 2004, Nieuwenhuis et al., 2003; for a summary see Folstein Van Petten, 2008), the dominance of N2 in the older adult group may also show that older adults were more reliant on cognitive control processes than younger adults in performing the task. Whereas this may be quantitative between-group difference, the marked N2 elicitation difference may also reflect a qualitative difference in the way the task was represented in the two groups. Szmalec et al. (2008) found no N2 elicited by tones in a simple detection task whereas the same tones elicited an N2 when presented in a discrimination context. In the present study, it could be 
speculated that younger adults framed the task essentially as offset-detection, whereas older adults framed it as a genuine discrimination task (a strategy-difference). The uniform between-group reaction time difference over the conditions fits this interpretation.

This strategy-difference notion is somewhat reminiscent of the distinction between proactive and reactive processing strategies suggested in the context of task-switching (Braver et al., 2008), proposing that older adults rely primarily on (spared) reactive processing strategies, whereas younger adults can utilize proactive strategies as well (Jimura and Braver, 2010; Bugg, 2014). In the present context, in order to structure the task as offset detection, one would have to identify the task-relevant time periods in which only the task-relevant offset (i.e. short tone offset) could occur and perform the detection task in these, while suspending task performance in other time-intervals. This hypothetical temporal structuring can be regarded as a form of proactive control. The ERP results neither support, nor contradict this interpretation. First, preparation-related ERPs preceding the tones, and short tone offsets (see below) are expectable for both strategies. Second, the withdrawal of attention in the taskirrelevant interval could be manifested in the amplitude decrease of the task-irrelevant offset ERP, the present design, however, does not allow the assessment whether such a decrease was present. Although one could argue that the presence of the offset-related ERP for long tones (marked by gray arrows at T8 in Figure 2 and 3) shows that participants attended the tones even in task-irrelevant intervals, this is not sufficient to dispel the strategy-difference idea, because long tone-offsets elicit an offset-related transient waveform even if the tones are unattended (Horváth, 2016).

Offset-related P1 and N1/N2 amplitudes were both shifted in the positive direction across conditions with increasing short tone duration (i.e. with increasing discrimination difficulty). We speculate that this pattern was caused by an overlap from the P3b which was temporally more spread, and therefore started earlier for longer short-tone durations. Such a 
temporal widening might be caused by the increasing uncertainty in the decision whether the task-relevant timepoint of the potential offset has been already reached or not. That is, for longer tones, participants are more likely to decide prematurely that the critical timepoint already passed than for shorter ones, which, on average, results in a P3b which is wider and starts earlier.

\subsection{ERP reflections of the information processing sequence in the paradigm}

Besides directly characterizing offset-related processing activity and its age-related differences, the results also allow a general delineation of the information processing sequence within the paradigm. The pattern of results seems to reflect the interaction of two effects, which differ in their tone duration-dependence. First, discrimination difficulty increases with increasing short/long duration ratios. Second, the constant stimulus timing patterns enable the use of tone-onset as a cue to prepare for the task-relevant time-point. Preparation efficiency follows a non-monotonous - reversed U-shaped - function, with an optimum point at a cue-target separation typically in the 150-300 ms interval (foreperiod effect, Bertelson, 1967; Müller-Gethmann et al., 2003). We speculate that in the present study the optimum was closer to the $300 \mathrm{~ms}$ onset-offset separation than to the $150 \mathrm{~ms}$, which is reflected in faster reaction times in the $300 \mathrm{vs} .750 \mathrm{~ms}$ condition than in the $150 \mathrm{vs} .750 \mathrm{~ms}$ condition. The close-to-optimal preparation efficiency in the $300 \mathrm{vs.} 750 \mathrm{~ms}$ condition may also have counteracted the increased difficulty in comparison to the $150 \mathrm{vs} .750 \mathrm{~ms}$ condition, which resulted in similar performance indices and similar preparatory activity as reflected in the ERPs. The drop in performance indices, and slower reaction times in the $450 \mathrm{vs} .750 \mathrm{~ms}$ condition probably reflect both the increase in discrimination difficulty, and that onsets did not allow for an efficient preparation for the task-relevant moment. The less steep negative ERP trend observed in the pre-tone interval, the lower-amplitude onset-related P1-N1, as well as the lower-amplitude offset-related N1, suggests that participants did not prepare for, and 
did not direct as much attention to tone-onsets, and consequently to offsets in this condition as in the other two.

\section{Conclusions}

In summary, the present study found no age-related differences in sensory ERP responses to tone offsets. In older adults, however, offset-related processing was dominated by an N2 reflecting the marked involvement of cognitive control-related processing activities. Because the N2 was present regardless discrimination difficulty, it is speculated that young adults represented the task as offset-detection, whereas old adults represented the task as duration-discrimination.

\section{Acknowledgements}

This work was supported by the Hungarian Scientific Research Fund (OTKA K104635), and the János Bolyai Research Scholarship of the Hungarian Academy of Sciences. Conflicts of interest: none. 


\section{References}

Alain C, McDonald K, Van Roon P. Effects of age and background noise on processing a mistuned harmonic in an otherwise periodic complex sound. Hear Res 2012;283:126135. doi:10.1016/j.heares.2011.10.007

Alain C, Roye A, Salloum C. Effects of age-related hearing loss and background noise on neuromagnetic activity from auditory cortex. Front Syst Neurosci 2014;8:8. doi:10.3389/fnsys.2014.00008

Alain C, Woods DL. Age-related changes in processing auditory stimuli during visual attention: Evidence for deficits in inhibitory control and sensory memory. Psychol Aging 1999;14:507-519. doi:10.1037/0882-7974.14.3.507

Alain C, Woods DL, Covarrubias D. Activation of duration-sensitive auditory cortical fields in humans. Electroencephalogr Clin Neurophysiol/Evoked Potentials Section 1997;104:531-539. doi: 10.1016/s0168-5597(97)00057-9

Amenedo E, Díaz F. Aging-related changes in processing of non-target and target stimuli during an auditory oddball task. Biol Psychol 1998;48:235-267. doi:10.1016/S03010511(98)00040-4

Anderer P, Pascual-Marqui RD, Semlitsch HV, Saletu B. Differential effects of normal aging on sources of standard N1, target N1 and target P300 auditory event-related brain potentials revealed by low resolution electromagnetic tomography (LORETA). Electroencephalogr Clin Neurophysiol 1998;108:160-174. doi:10.1016/S01685597(97)00080-4

Anderer P, Semlitsch HV, Saletu B. Multichannel auditory event-related brain potentials: effects of normal aging on the scalp distribution of N1, P2, N2 and P300 latencies and amplitudes. Electroencephalogr Clin Neurophysiol 1996;99:458-472.

doi:10.1016/S0013-4694(96)96518-9 
Bakeman R. Recommended effect size statistics for repeated measures designs. Behav Res Methods 2005;37:379-384. doi:10.3758/BF03192707

Bertelson P. The time course of preparation. Q J Exp Psychol 1967;19:272-279. doi:10.1080/14640746708400102

Berti S, Schröger E. A comparison of auditory and visual distraction effects: behavioral and event-related indices. Cogn Brain Res 2001;10:265-273. doi:10.1016/S09266410(00)00044-6

Bertoli S, Smurzynski J, Probst R. Effects of age, age-related hearing loss, and contralateral cafeteria noise on the discrimination of small frequency changes: psychoacoustic and electrophysiological measures. Jaro-J Assoc Res Oto 2005;6:207-222. doi:10.1007/s10162-005-5029-6

Bharadwaj HM, Masud S, Mehraei G, Verhulst S, Shinn-Cunningham BG. Individual Differences Reveal Correlates of Hidden Hearing Deficits. J Neurosci 2015;35:21612172. doi:10.1523/JNEUROSCI.3915-14.2015

Braver TS, Gray JR, Burgess GC. Explaining the Many Varieties of Working Memory Variation: Dual Mechanisms of Cognitive Control; in Conway A, Jarrold C, Kane M, Miyake A, Towse J (eds): Variation in Working Memory. Oxford University Press, 2008, pp 76-106.

Bugg JM. Evidence for the sparing of reactive cognitive control with age. Psychol Aging 2014;29:115-127. doi:10.1037/a0035270

Chao LL, Knight RT. Age-related prefrontal alterations during auditory memory. Neurobiol Aging 1997;18:87-95. doi:10.1016/S0197-4580(96)00161-3

Crowley KE, Colrain IM. A review of the evidence for P2 being an independent component process: age, sleep and modality. Clin Neurophysiol 2004;115:732-744. doi:10.1016/j.clinph.2003.11.021 
Czigler I, Csibra G, Csontos A. Age and inter-stimulus interval effects on event-related potentials to frequent and infrequent auditory stimuli. Biol Psychol 1992;33:195-206. doi:10.1016/0301-0511(92)90031-O

Davis H, Zerlin S. Acoustic Relations of the Human Vertex Potential. J Acoust Soc Am 1966;39:109. doi:10.1121/1.1909858

Donkers FCL, van Boxtel GJM. The N2 in go/no-go tasks reflects conflict monitoring not response inhibition. Brain Cogn 2004;56:165-176. doi:10.1016/j.bandc.2004.04.005

Fabiani M, Low KA, Wee E, Sable JJ, Gratton G. Reduced suppression or labile memory? Mechanisms of inefficient filtering of irrelevant information in older adults. J Cogn Neurosci 2006;18:637-650. doi:10.1162/jocn.2006.18.4.637

Fishman YI, Steinschneider M. Temporally dynamic frequency tuning of population responses in monkey primary auditory cortex. Hear Res 2009;254:64-76. doi: 10.1016/j.heares.2009.04.010

Folstein JR, Van Petten C. Influence of cognitive control and mismatch on the N2 component of the ERP: A review. Psychophysiology 2008;45:152-170. doi:10.1111/j.14698986.2007.00602.x

Ford JM, Pfefferbaum A. Event-related potentials and eyeblink responses in automatic and controlled processing: effects of age. Electroencephalogr Clin Neurophysiol 1991;78:361-377. doi:10.1016/0013-4694(91)90098-O

Friedman D, Cycowicz YM, Gaeta H. The novelty P3: an event-related brain potential (ERP) sign of the brain's evaluation of novelty. Neurosci Biobehav R 2001;25:355-373. doi:10.1016/S0149-7634(01)00019-7

Gates GA, Mills JH. Presbycusis. Lancet 2005;366:1111-1120.

Gazzaley A, Cooney JW, Rissman J, D’Esposito M. Top-down suppression deficit underlies working memory impairment in normal aging. Nat Neurosci 2005;8:1298-1300. 
doi:10.1038/nn1543

Godey B, Schwartz D, De Graaf JB, Chauvel P, Liegeois-Chauvel C. Neuromagnetic source localization of auditory evoked fields and intracerebral evoked potentials: a comparison of data in the same patients. Clin Neurophysiol 2001;112:1850-1859. doi:10.1016/S1388-2457(01)00636-8

Goodin DS, Squires KC, Henderson BH, Starr A. Age-related variations in evoked potentials to auditory stimuli in normal human subjects. Electroencephalogr Clin Neurophysiol 1978;44:447-458. doi:10.1016/0013-4694(78)90029-9

Halgren E, Baudena P, Clarke JM, Heit G, Liégeois C, Chauvel P, et al. Intracerebral potentials to rare target and distractor auditory and visual stimuli. I. Superior temporal plane and parietal lobe. Electroencephalogr Clin Neurophysiol 1995;94:191-220.

Hansen JC, Hillyard SA. Endogeneous brain potentials associated with selective auditory attention. Electroencephalogr Clin Neurophysiol 1980;49:277-290. doi:10.1016/00134694(80)90222-9

Hari R, Pelizzone M, Mäkelä JP, Hällström J, Leinonen L, Lounasmaa OV. Neuromagnetic responses of the human auditory cortex to on- and offsets of noise bursts. Audiology 1987;26:31-43. doi:10.3109/00206098709078405

Harkrider AW, Plyler PN, Hedrick MS. Effects of hearing loss and spectral shaping on identification and neural response patterns of stop-consonant stimuli. J Acoust Soc Am 2006;120:915. doi:10.1121/1.2204588

Harris KC, Wilson S, Eckert MA, Dubno JR. Human evoked cortical activity to silent gaps in noise: effects of age, attention, and cortical processing speed. Ear Hear 2012;33:330 339. doi:10.1097/AUD.0b013e31823fb585

Hasher L, Zacks RT, May CP. Inhibitory control, circadian arousal, and age.; in Gopher D, Koriat A (eds): Attention and Performance XVII, Cognitive Regulation of 
Performance: Interaction of Theory and Application. Cambridge, Mass., MIT Press, 1999, pp 653-675.

Hasher L, Zacks RT. Working memory, comprehension and aging: a review and a new view; in Bower GH (ed): The Psychology of Learning and Motivation: Advances in Research and Theory. New York, Academic Press, 1988, pp 193-225.

He J. On and off pathways segregated at the auditory thalamus of the guinea pig. J Neurosci 2001;21:8672-8679.

He J. OFF responses in the auditory thalamus of the guinea pig. J Neurophysiol 2002;88:2377-2386. doi:10.1152/jn.00083.2002

Hillyard SA, Hink RF, Schwent VL, Picton TW. Electrical signs of selective attention in the human brain. Science 1973;182:177-180. doi:10.1126/science.182.4108.177

Hillyard SA, Picton TW. On and off components in the auditory evoked potential. Perception \& psychophysics 1978;24:391-398. doi:10.3758/bf03199736

Horváth J, Czigler I, Birkás E, Winkler I, Gervai J. Age-related differences in distraction and reorientation in an auditory task. Neurobiol Aging 2009;30:1157-1172. doi:10.1016/j.neurobiolaging.2007.10.003

Horváth J. Sensory ERP effects in auditory distraction: did we miss the main event? Psychol Res 2014;78:339-348. doi:10.1007/s00426-013-0507-7

Horváth J. Attention-dependent sound offset-related brain potentials. Psychophysiology 2016;53:663-677. doi:10.1111/psyp.12607

Humes LE, Dubno JR, Gordon-Salant S, Lister JJ, Cacace AT, Cruickshanks KJ, et al. Central Presbycusis: A Review and Evaluation of the Evidence. J Am Acad Audiol 2012;23:635-666. doi:10.3766/jaaa.23.8.5

Humes LE, Kewley-Port D, Fogerty D, Kinney D. Measures of hearing threshold and temporal processing across the adult lifespan. Hear Res 2010;264:30-40. 
doi:10.1016/j.heares.2009.09.010

Humes LE. Speech understanding in the elderly. J Am Acad Audiol 1996;7:161-167.

Jimura K, Braver TS. Age-related shifts in brain activity dynamics during task switching. Cereb Cortex 2010;20:1420-1431. doi:10.1093/cercor/bhp206

Kiesel A, Miller J, Jolicœur P, Brisson B. Measurement of ERP latency differences: A comparison of single-participant and jackknife-based scoring methods.

Psychophysiology 2008;45:250-274. doi:10.1111/j.1469-8986.2007.00618.x

Kovacevic S, Qualls C, Adair JC, Hudson D, Woodruff CC, Knoefel J, et al. Age-related effects on superior temporal gyrus activity during an auditory oddball task. Neuroreport 2005;16:1075-1079. doi:10.1097/00001756-200507130-00009

Liegeois-Chauvel C, Musolino A, Badier JM, Marquis P, Chauvel P. Evoked potentials recorded from the auditory cortex in man: evaluation and topography of the middle latency components. Electroencephalogr Clin Neurophysiol 1994;92:204-214.

Lütkenhöner B, Steinsträter O. High-precision neuromagnetic study of the functional organization of the human auditory cortex. Audiol Neurootol 1998;3:191-213. Macmillan NA, Creelman CD. Detection theory: a user's guide. 2nd ed Mahwah, N.J, Lawrence Erlbaum Associates, 2005.

Marshall L. Auditory processing in aging listeners. J Speech Hear Disord 1981;46:226-240. doi:10.1044/jshd.4603.226

McEvoy L, Mäkelä JP, Hämäläinen M, Hari R. Effect of interaural time differences on middle-latency and late auditory evoked magnetic fields. Hear Res 1994;78:249-257. doi:10.1016/0378-5955(94)90031-0

Morita T, Naito Y, Nagamine T, Fujiki N, Shibasaki H, Ito J. Enhanced activation of the auditory cortex in patients with inner-ear hearing impairment: a magnetoencephalographic study. Clin Neurophysiol 2003;114:851-859. 
doi:10.1016/S1388-2457(03)00033-6

Müller-Gethmann H, Ulrich R, Rinkenauer G. Locus of the effect of temporal preparation: Evidence from the lateralized readiness potential. Psychophysiology 2003;40:597611.

Näätänen R, Gaillard AW, Mäntysalo S. Early selective-attention effect on evoked potential reinterpreted. Acta Psychol (Amst) 1978;42:313-329. doi:10.1016/00016918(78)90006-9

Näätänen R, Picton T. The N1 wave of the human electric and magnetic response to sound: A review and an analysis of the component structure. Psychophysiology 1987;24:375425. doi:10.1111/j.1469-8986.1987.tb00311.x

Näätänen R. Processing negativity: An evoked-potential reflection of selective attention. Psychol Bull 1982;92:605-640. doi:10.1037//0033-2909.92.3.605

Näätänen R. The role of attention in auditory information processing as revealed by eventrelated potentials and other brain measures of cognitive function. Behav Brain Sci 1990;13:201-233. doi:10.1017/S0140525X00078407

Nakagawa K, Otsuru N, Inui K, Kakigi R. Change-related auditory P50: A MEG study. Neuroimage 2014;86:131-137. doi:10.1016/j.neuroimage.2013.07.082

Nieuwenhuis S, Yeung N, Cohen JD. Stimulus modality, perceptual overlap, and the go/no-go N2. Psychophysiology 2004;41:157-160. doi:10.1046/j.1469-8986.2003.00128.x

Nieuwenhuis S, Yeung N, Van Den Wildenberg W, Ridderinkhof KR. Electrophysiological correlates of anterior cingulate function in a go/no-go task: effects of response conflict and trial type frequency. Cogn Affect Behav Neurosci 2003;3:17-26. doi:10.3758/cabn.3.1.17

Noda K, Tonoike M, Doi K, Koizuka I, Yamaguchi M, Seo R, et al. Auditory evoked offresponse: its source distribution is different from that of on-response. Neuroreport 
1998;9:2621-2625. doi:10.1097/00001756-199808030-00036

Nuwer MR, Comi G, Emerson R, Fuglsang-Frederiksen A, Guérit J-M, Hinrichs H, et al. IFCN standards for digital recording of clinical EEG. Electroencephalogr Clin Neurophysiol 1998;106:259-261. doi:10.1016/S0013-4694(97)00106-5

O’Connell MN, Falchier A, McGinnis T, Schroeder CE, Lakatos P. Dual mechanism of neuronal ensemble inhibition in primary auditory cortex. Neuron 2011;69:805-817. doi: 10.1016/j.neuron.2011.01.012

Olejnik S, Algina J. Generalized eta and omega squared statistics: Measures of effect size for some common research designs. Psychol Methods 2003;8:434-447. doi:10.1037/1082-989X.8.4.434

Onishi S, Davis H. Effects of duration and rise time of tone bursts on evoked V potentials. J Acoust Soc Am 1968;44:582-591. doi:10.1121/1.1911124

Pantev C, Eulitz C, Hampson S, Ross B, Roberts LE. The auditory evoked “off” response: sources and comparison with the "on" and the "sustained" responses. Ear Hear 1996;17:255-265. doi:10.1097/00003446-199606000-00008

Peelle JE, Wingfield A. The Neural Consequences of Age-Related Hearing Loss. Trends Neurosci 2016;39:486-497. doi:10.1016/j.tins.2016.05.001

Pekkonen E, Huotilainen M, Virtanen J, Sinkkonen J, Rinne T, llmoniemi RJ, et al. Agerelated functional differences between auditory cortices: a whole- head MEG study. Neuroreport 1995;6:1803-1806. doi:10.1097/00001756-199509000-00023

Pfefferbaum A, Ford JM, Roth WT, F. Hopkins W, Kopell BS. Event-related potential changes in healthy aged females. Electroencephalogr Clin Neurophysiol 1979;46:8186. doi:10.1016/0013-4694(79)90052-X

Pfefferbaum A, Ford JM, Wenegrat BG, Roth WT, Kopell BS. Clinical application of the P3 component of event-related potentials. I. Normal aging. Electroencephalogr Clin 
Neurophysiol 1984;59:85-103. doi:10.1016/0168-5597(84)90026-1

Picton TW, Hillyard SA, Krausz HI, Galambos R. Human auditory evoked potentials. I:

Evaluation of components. Electroencephalogr Clin Neurophysiol 1974;36:179-190.

Plack CJ, Leger A, Prendergast G, Kluk K, Guest H, Munro KJ. Toward a Diagnostic Test for Hidden Hearing Loss. Trends Hear 2016;20. doi:10.1177/2331216516657466

Ponton C, Eggermont JJ, Khosla D, Kwong B, Don M. Maturation of human central auditory system activity: separating auditory evoked potentials by dipole source modeling. Clin Neurophysiol 2002;113:407-420. doi:10.1016/S1388-2457(01)00733-7

Qin L, Chimoto S, Sakai M, Wang J, Sato Y. Comparison Between Offset and Onset Responses of Primary Auditory Cortex ON-OFF Neurons in Awake Cats. J Neurophysiol 2007;97:3421-3431. doi:10.1152/jn.00184.2007

Ramamurthy DL, Recanzone GH. Spectral and spatial tuning of onset and offset response functions in auditory cortical fields A1 and CL of rhesus macaques. J Neurophysiol 2017;117:966-986. doi:10.1152/jn.00534.2016

Recanzone GH. Response profiles of auditory cortical neurons to tones and noise in behaving macaque monkeys. Hear Res 2000;150:104-118. doi:10.1016/S0378-5955(00)001945

Ritter W, Simson R, Vaughan H, Friedman D. A brain event related to the making of a sensory discrimination. Science 1979;203:1358-1361. doi:10.1126/science.424760

Ross B, Snyder JS, Aalto M, McDonald KL, Dyson BJ, Schneider B, et al. Neural encoding of sound duration persists in older adults. NeuroImage 2009;47:678-687. doi: 10.1016/j.neuroimage.2009.04.051

Ross B, Tremblay K. Stimulus experience modifies auditory neuromagnetic responses in young and older listeners. Hear Res 2009;248:48-59. doi:10.1016/j.heares.2008.11.012 
Scherg M, Vajsar J, Picton TW. A Source Analysis of the Late Human Auditory Evoked Potentials. J Cogn Neurosci 1989;1:336-355. doi:10.1162/jocn.1989.1.4.336

Scherg M, Von Cramon D. Evoked dipole source potentials of the human auditory cortex. Electroencephalogr Clin Neurophysiol Evoked Potentials 1986;65:344-360. doi:10.1016/0168-5597(86)90014-6

Scholl B, Gao X, Wehr M. Nonoverlapping Sets of Synapses Drive On Responses and Off Responses in Auditory Cortex. Neuron 2010;65:412-421. doi:10.1016/j.neuron.2010.01.020

Smith DB, Michalewski HJ, Brent GA, Thompson LW. Auditory averaged evoked potentials and aging: factors of stimulus, task and topography. Biol Psychol 1980;11:135-151. doi:10.1016/0301-0511(80)90048-4

Suga N. Single unit activity in cochlear nucleus and inferior colliculus of echo-locating bats. J Physiol 1964;172:449-474.

Stothart G, Kazanina N. Auditory perception in the aging brain: the role of inhibition and facilitation in early processing. Neurobiol Aging 2016;47:23-34. doi:10.1016/j.neurobiolaging.2016.06.022

Szmalec A, Verbruggen F, Vandierendonck A, De Baene W, Verguts T, Notebaert W. Stimulus ambiguity elicits response conflict. Neurosci Lett 2008;435:158-162. doi:10.1016/j.neulet.2008.02.023

Vaughan Jr HG, Ritter W. The sources of auditory evoked responses recorded from the human scalp. Electroencephalogr Clin Neurophysiol 1970;28:360-367. doi:10.1016/0013-4694(70)90228-2

Verkindt C, Bertrand O, Thevenet M, Pernier J. Two auditory components in the 130-230 ms range disclosed by their stimulus frequency dependence: Neuroreport 1994;5:11891192. doi:10.1097/00001756-199406020-00007 
Volosin M, Gaál ZsA, Horváth J. Task-optimal auditory attention set restored as fast in older as in younger adults after distraction. Biol Psychol 2017;126:71-81. doi:10.1016/S0301-0511(98)00040-4

Volosin M, Horváth J. Knowledge of sequence structure prevents auditory distraction: An ERP study. Int J Psychophysiol 2014;92:93-98. doi:10.1016/j.ijpsycho.2014.03.003

Wayne RV, Johnsrude IS. A review of causal mechanisms underlying the link between agerelated hearing loss and cognitive decline. Ageing Res Rev 2015;23:154-166. doi:10.1016/j.arr.2015.06.002

Woldorff MG, Hillyard SA. Modulation of early auditory processing during selective listening to rapidly presented tones. Electroencephalogr Clin Neurophysiol $1991 ; 79: 170-191$.

Wolpaw JR, Penry JK. A temporal component of the auditory evoked response. Electroencephalogr Clin Neurophysiol 1975;39:609-620. doi:10.1016/00134694(75)90073-5

Yamashiro K, Inui K, Otsuru N, Kakigi R. Change-related responses in the human auditory cortex: An MEG study: Change-related responses in the human auditory cortex. Psychophysiology 2011;48:23-30. doi:10.1111/j.1469-8986.2010.01038.x 


\section{Tables}

\begin{tabular}{|c|c|c|c|c|}
\hline & IQ (WAIS-IV) & \multicolumn{3}{|c|}{ Hearing thresholds (dB SPL) } \\
\hline & & $500 \mathrm{~Hz}$ & $1000 \mathrm{~Hz}$ & $2000 \mathrm{~Hz}$ \\
\hline Younger & $106 \pm 11$ & $9 \pm 5$ & $3 \pm 5$ & $6 \pm 6$ \\
\hline Older & $121 \pm 15$ & $17 \pm 9$ & $10 \pm 6$ & $17 \pm 10$ \\
\hline Welch & $\mathrm{t}(34.71)=3.611$, & $\mathrm{t}(29.93)=3.502$, & $\mathrm{t}(35.11)=3.878$ & $\mathrm{t}(32.14)=4.426$ \\
$\mathrm{t}$-test results & $\mathrm{p}<0.001$ & $\mathrm{p}=0.001$ & $\mathrm{p}<0.001$ & $\mathrm{p}<0.001$ \\
\hline
\end{tabular}

Table 1. Mean IQ scores and hearing thresholds (and standard deviations) in the younger and older adult groups, compared by two-sample Welch t-tests. Note that in the experiment, tone intensity was individually adjusted to $50 \mathrm{~dB}$ above the hearing threshold level measured with a continuous version of the tone presented in the experiment.

\begin{tabular}{|c|c|c|c|c|c|c|}
\hline & \multicolumn{3}{|c|}{ Young } & \multicolumn{3}{c|}{ Old } \\
\hline & $150 \mathrm{vs.}$ & $300 \mathrm{vs.}$ & $450 \mathrm{vs}$. & $150 \mathrm{vs}$. & $300 \mathrm{vs}$. & $450 \mathrm{vs.}$ \\
& $750 \mathrm{~ms}$ & $750 \mathrm{~ms}$ & $750 \mathrm{~ms}$ & $750 \mathrm{~ms}$ & $750 \mathrm{~ms}$ & $750 \mathrm{~ms}$ \\
\hline $\mathrm{P} 1$ & 102 & 104 & 107 & 113 & 112 & 116 \\
\hline $\mathrm{N} 1 / \mathrm{N} 2$ & 164 & 167 & 185 & 217 & 224 & 236 \\
\hline $\mathrm{P} 3 \mathrm{~b}$ & 319 & 309 & 344 & 342 & 347 & 339 \\
\hline
\end{tabular}

Table 2. Offset-related group-average P1, N1/N2 (both measured at Cz) and P3b peak latencies (measured at $\mathrm{Pz}$ ) in the short-minus-long difference waveforms in the three conditions, in the younger and older adult groups. 
Figures
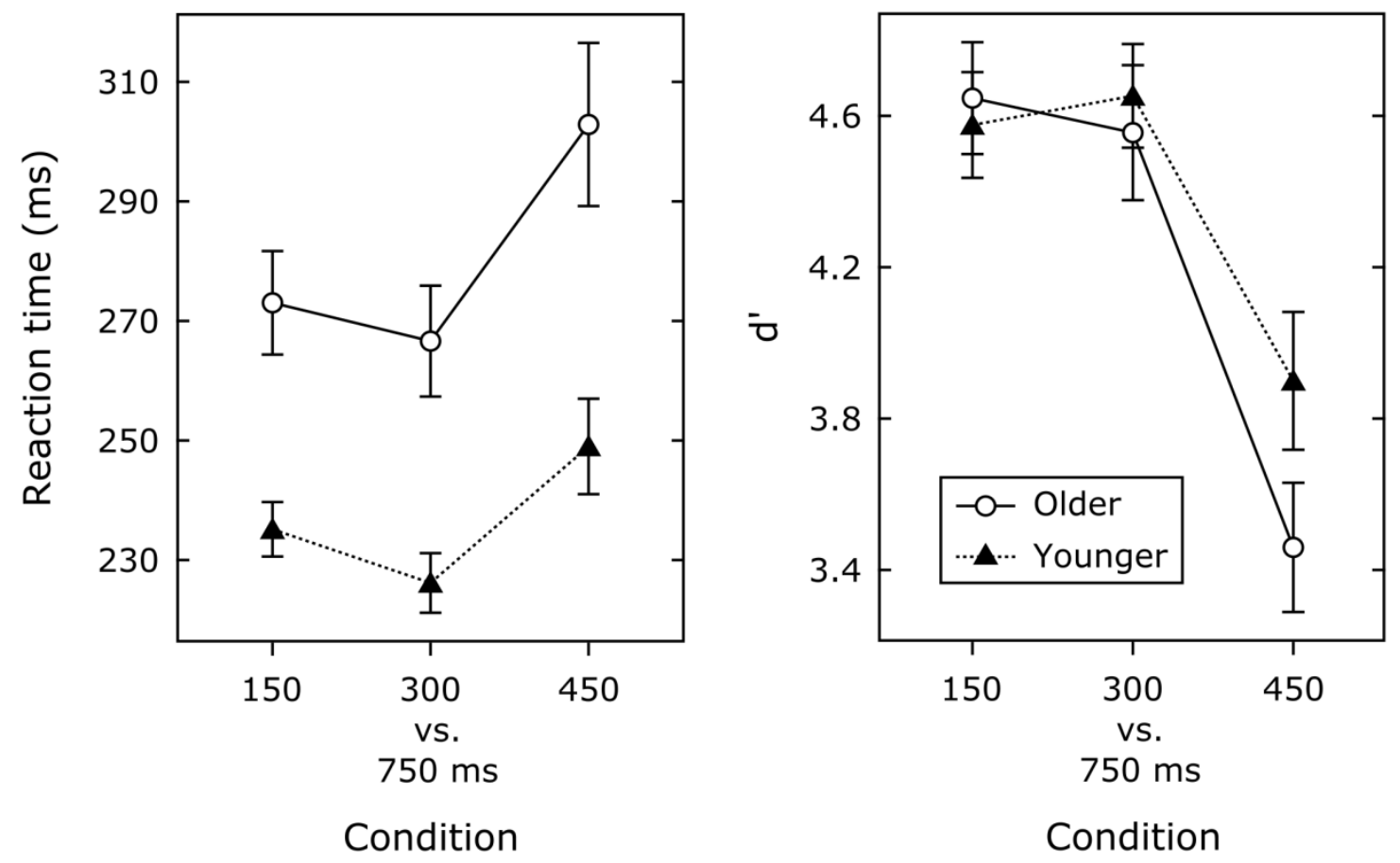

Figure 1. Group-average reaction times (left) and d' sensitivity scores (right) in the three conditions. Whiskers indicate standard errors. 

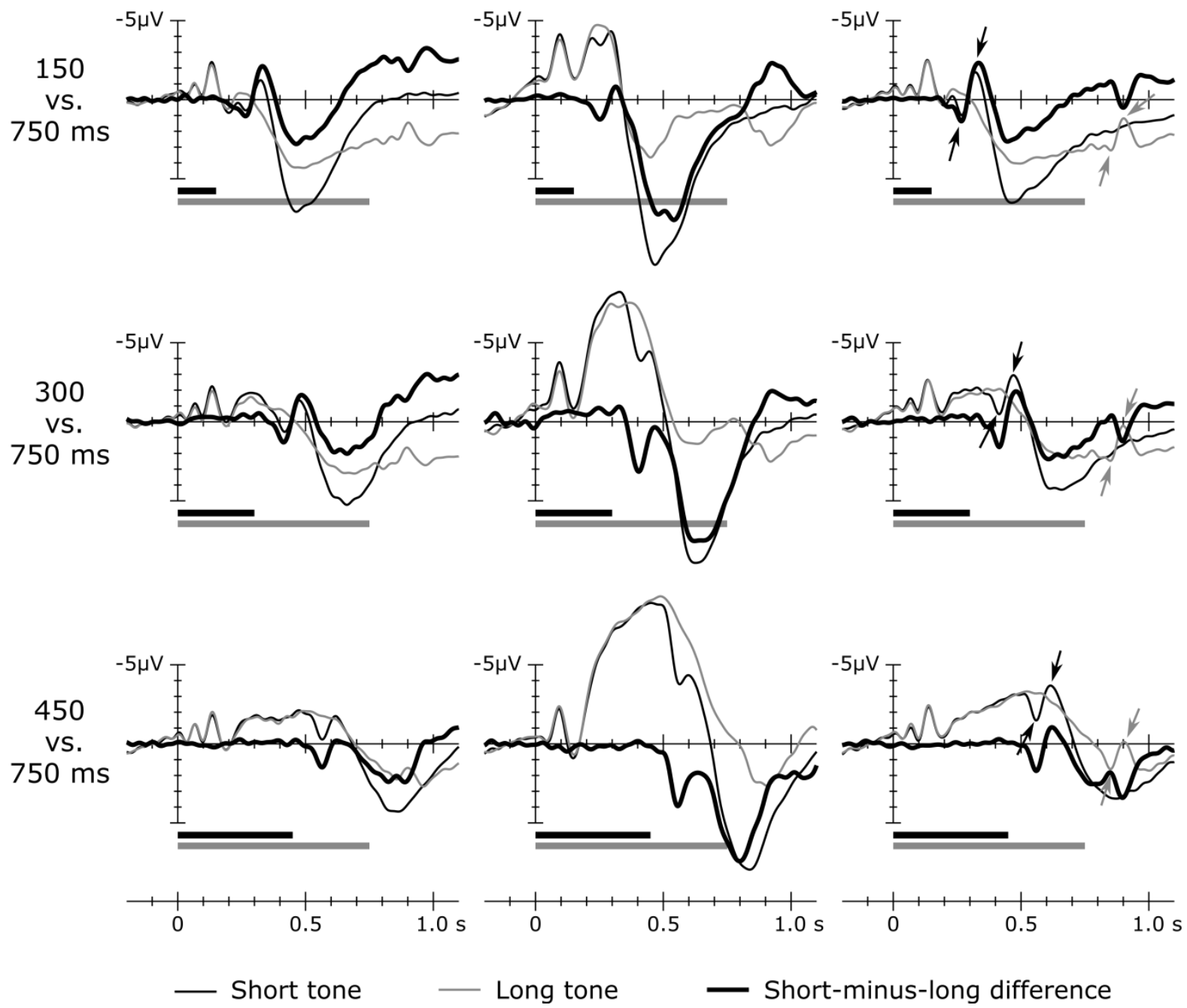

Figure 2. Group-average ERPs elicited at the $\mathrm{T} 7$ (left), $\mathrm{Cz}$ (middle), and $\mathrm{T} 8$ (right) electrodes for the short (thin black curves) and long tones (thin gray curves) in the three conditions (each presented in a single row) in the younger adult group, and the corresponding short-minus-long difference waveforms (thick black curves). Tone durations are represented as black (short) and gray (long) bars under the horizontal axes. Black and gray arrows indicate the offsetrelated $\mathrm{P} 1$ and $\mathrm{N} 1$ waveforms at the T8 electrode for the short and the long tones respectively. 

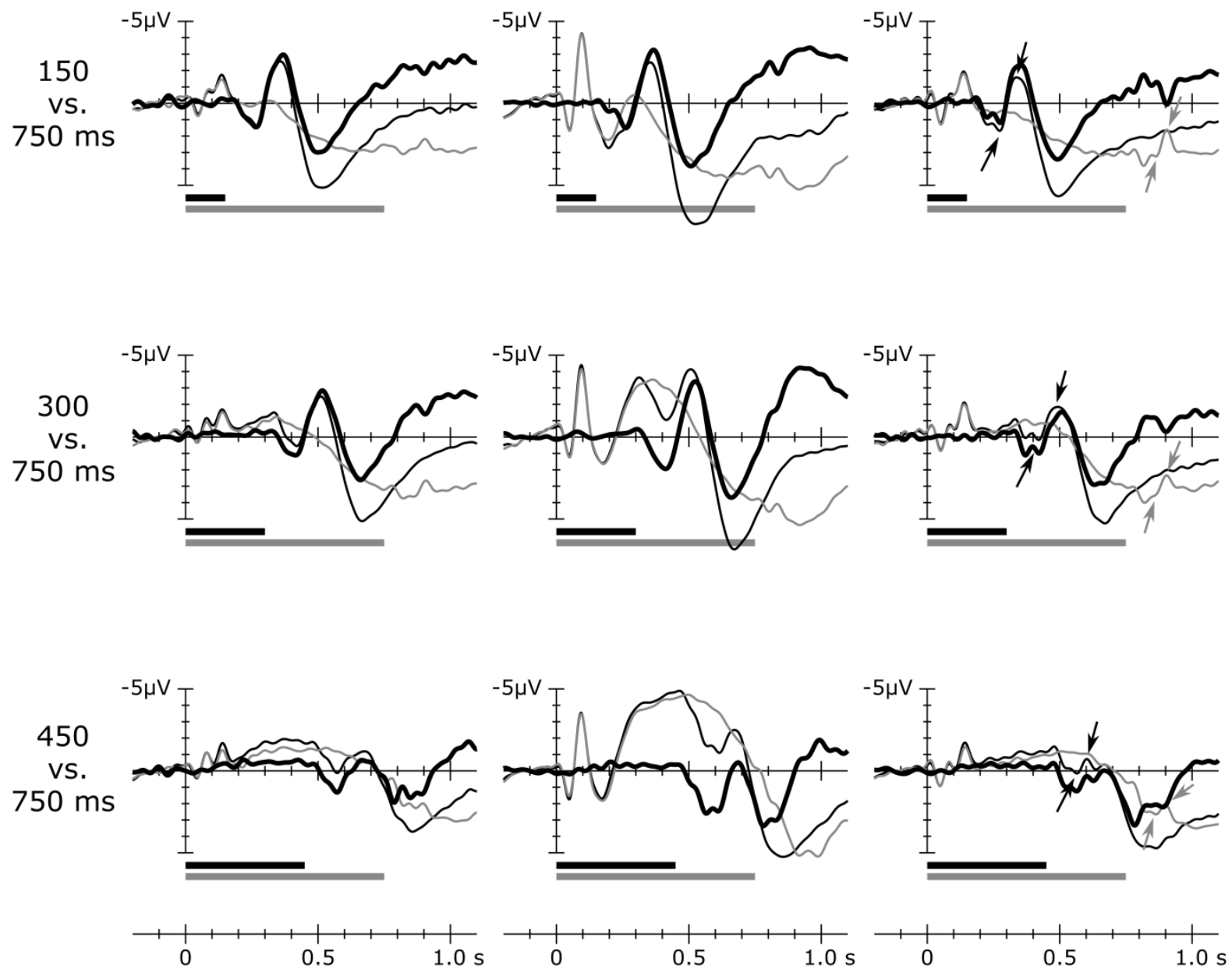

- Short tone

Long tone

- Short-minus-long difference

Figure 3. Group-average ERPs elicited at the $\mathrm{T} 7$ (left), $\mathrm{Cz}$ (middle), and $\mathrm{T} 8$ (right) electrodes for the short (thin black curves) and long tones (thin gray curves) in the three conditions (each presented in a single row) in the older adult group, and the corresponding short-minus-long difference waveforms (thick black curves). Tone durations are represented as black (short) and gray (long) bars under the horizontal axes. Black and gray arrows indicate the offsetrelated P1 and N1 waveforms at the T8 electrode for the short and the long tones respectively. 


\section{Short-minus-long difference waveforms}

T7

$\mathrm{Cz}$

T8
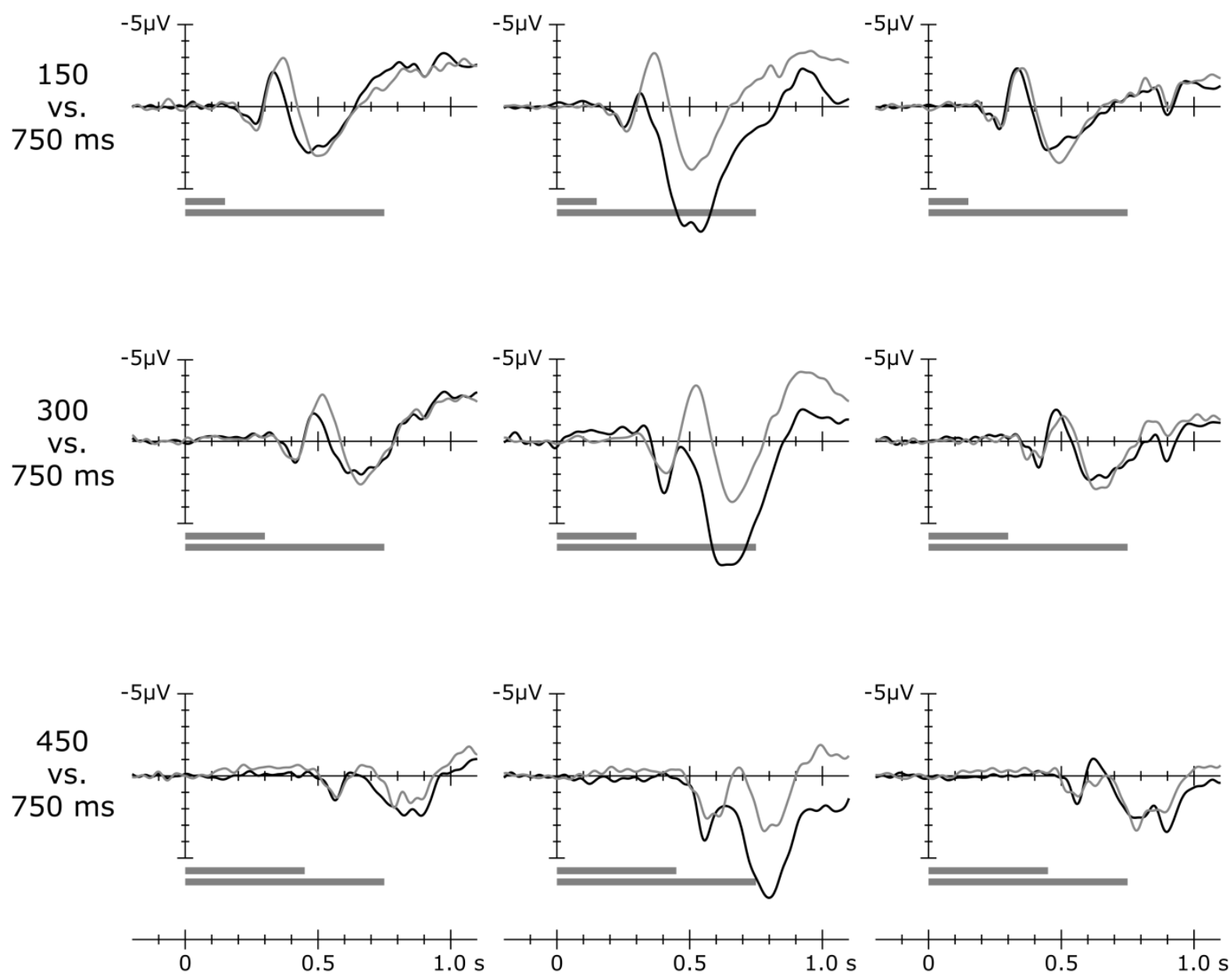

- Younger adults

Older adults

Figure 4. Group-average short-minus-long difference waveforms elicited at the $\mathrm{T} 7$ (left), $\mathrm{Cz}$ (middle), and T8 (right) electrodes in the younger adult (black curves) and older adult group (gray curves) in the three conditions (each presented in a single row). Tone durations in the given conditions are represented as gray bars under the horizontal axes. 




Figure 5. Group-average offset-related topographical ERP distributions (average amplitudes measured in the short-minus-long difference waveforms, in $20 \mathrm{~ms}$ windows centered at the peak latencies described in Table 2) for the two groups in the three conditions for the P1, $\mathrm{N} 1 / \mathrm{N} 2$, and $\mathrm{P} 3 \mathrm{~b}$ time ranges. 


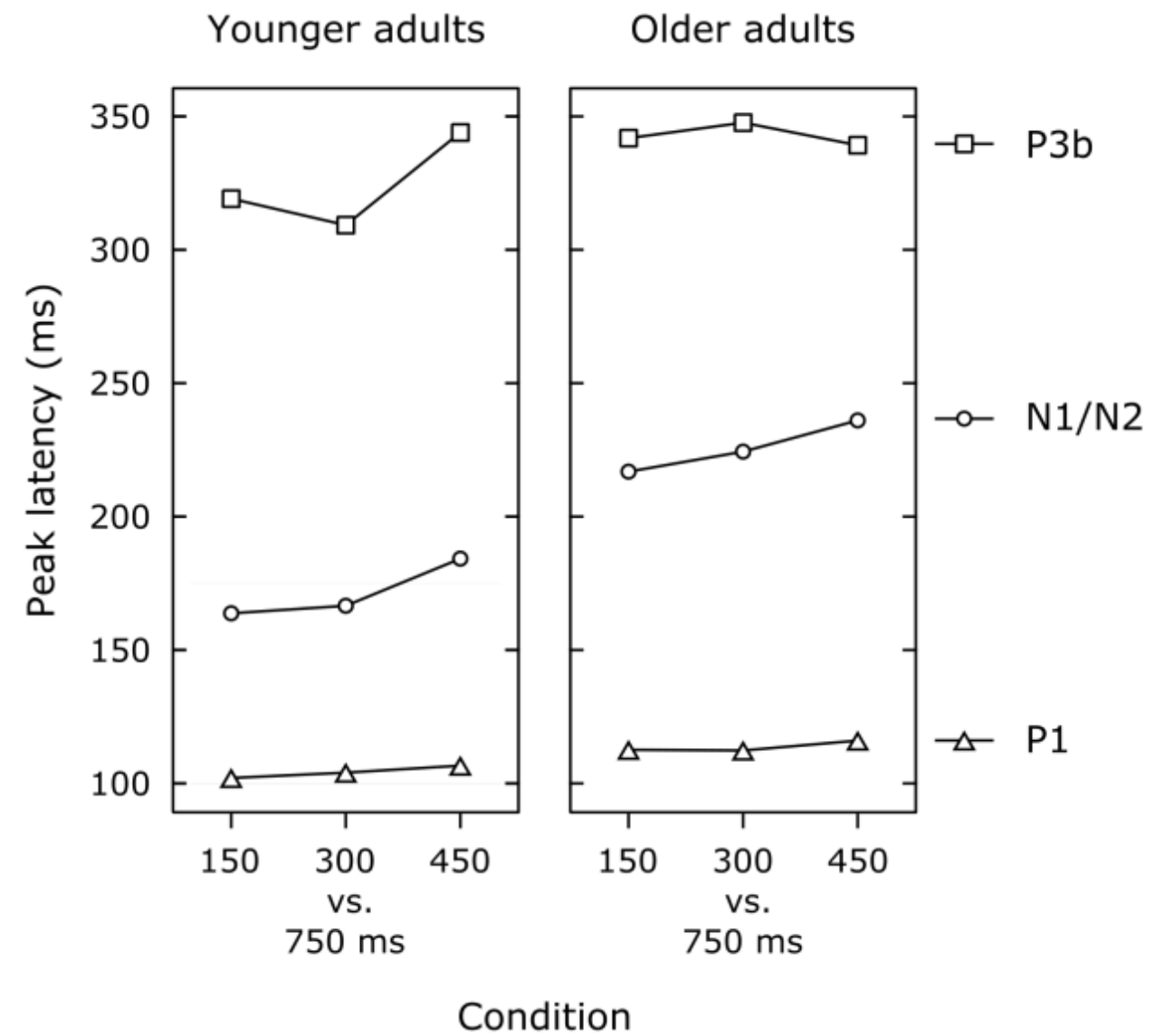

Figure 6. Group-mean jackknife peak latencies of the offset-related P1, N1/N2, and P3b measured at $\mathrm{Cz}$ in the short-minus-long difference waveforms in the three conditions. 
T7
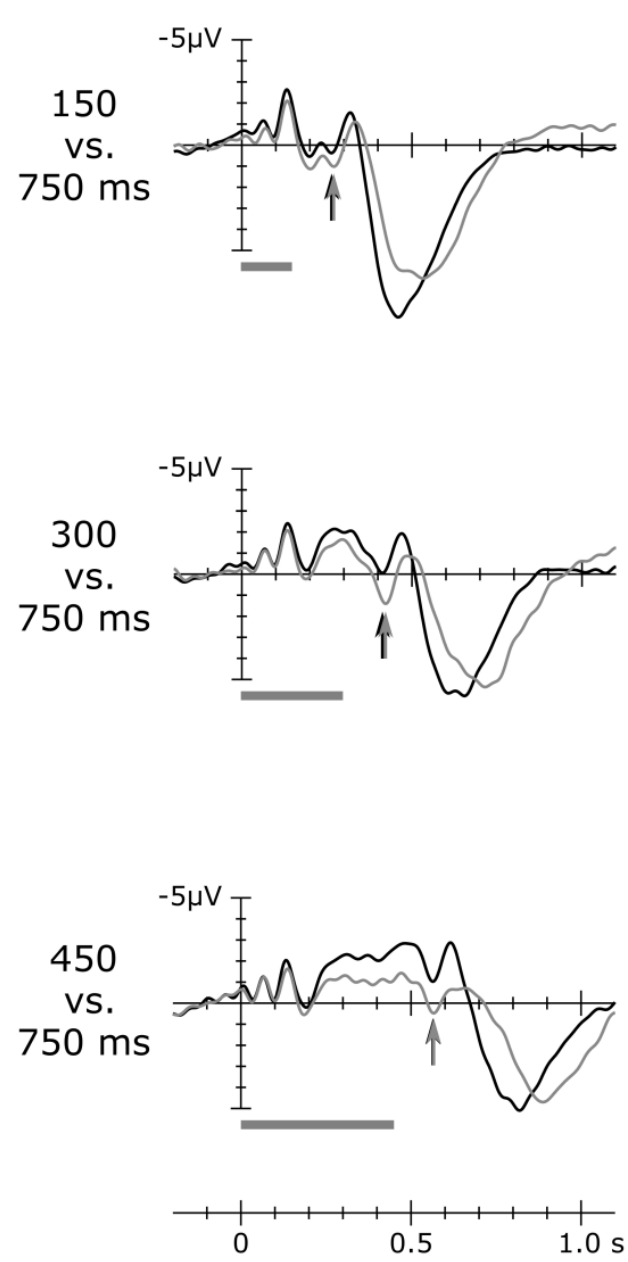

$\mathrm{Cz}$
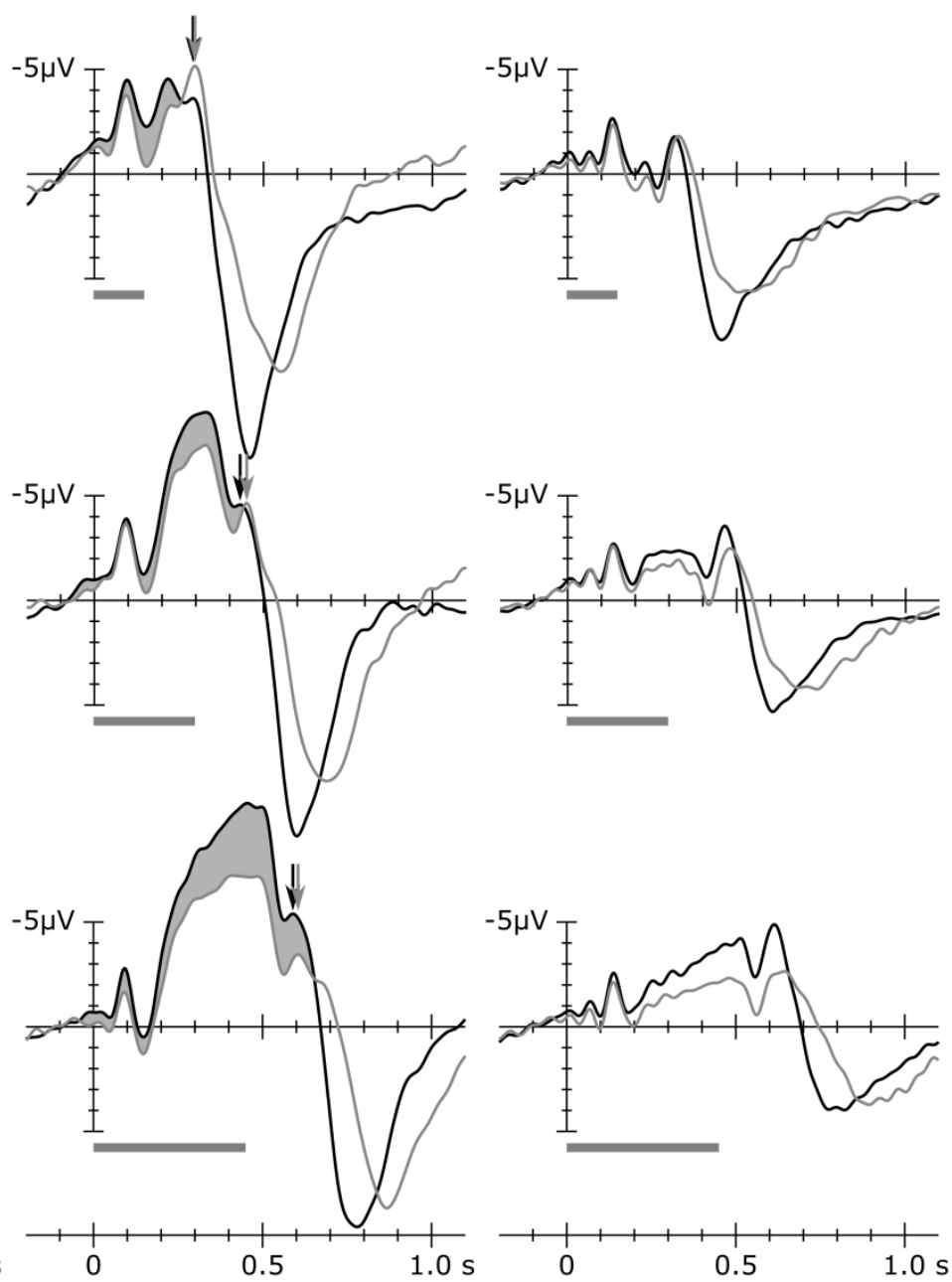

— Fast responses

Figure 7. Group-average ERPs elicited by short tones in trials with below-median (black curves) and above-median reaction times (gray curves) at the $\mathrm{T} 7$ (left), $\mathrm{Cz}$ (middle), and $\mathrm{T} 8$ (right) electrodes, in the three conditions (each presented in a single row) in the younger adult group. Short tone durations in the given conditions are represented as gray bars under the horizontal axes. Offset-related P1 peak latencies are indicated by arrows with colors corresponding to the curves at $\mathrm{T} 7$, offset-related N1/N2s peak latencies are indicated by arrows with colors corresponding to the curves at $\mathrm{Cz}$. The light gray shading between the two curves at $\mathrm{Cz}$ highlight a sustained difference in ERP activity preceding the offset-related waveforms. 


\section{Older adults}

T7

$\mathrm{Cz}$

T8
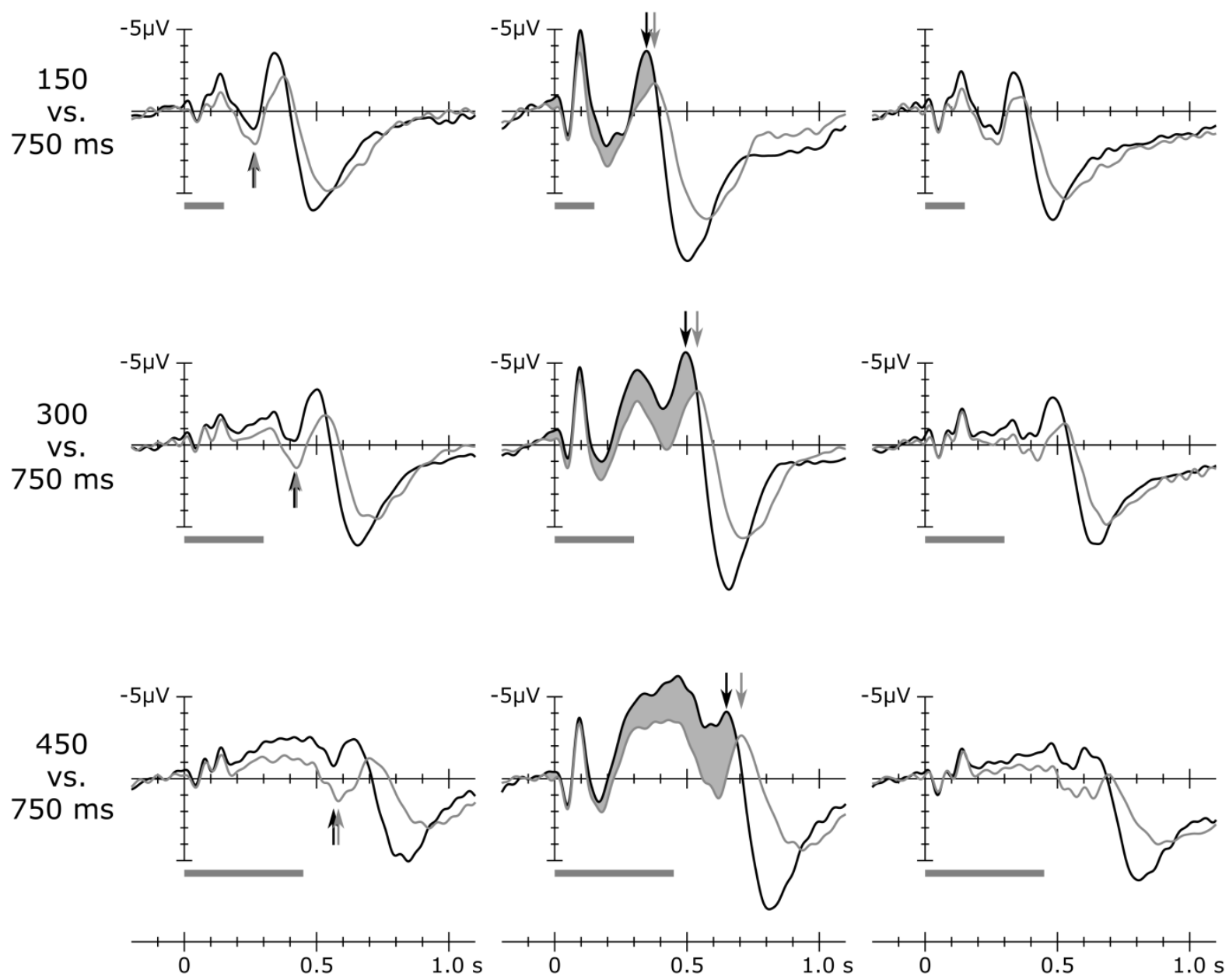

— Fast responses

— Slow responses

Figure 8. Group-average ERPs elicited by short tones in trials with below-median (black curves) and above-median reaction times (gray curves) at $\mathrm{T} 7$ (left), $\mathrm{Cz}$ (middle), and $\mathrm{T} 8$ (right) electrodes, in the three conditions (each presented in a single row) in the older adult group. Short tone durations in the given conditions are represented as gray bars under the horizontal axes. Offset-related P1 peak latencies are indicated by arrows with colors corresponding to the curves at T7, offset-related N1/N2s latencies are indicated by arrows with colors corresponding to the curves at $\mathrm{Cz}$. The light gray shading between the two curves at $\mathrm{Cz}$ highlight a sustained difference in ERP activity preceding the offset-related waveforms. 


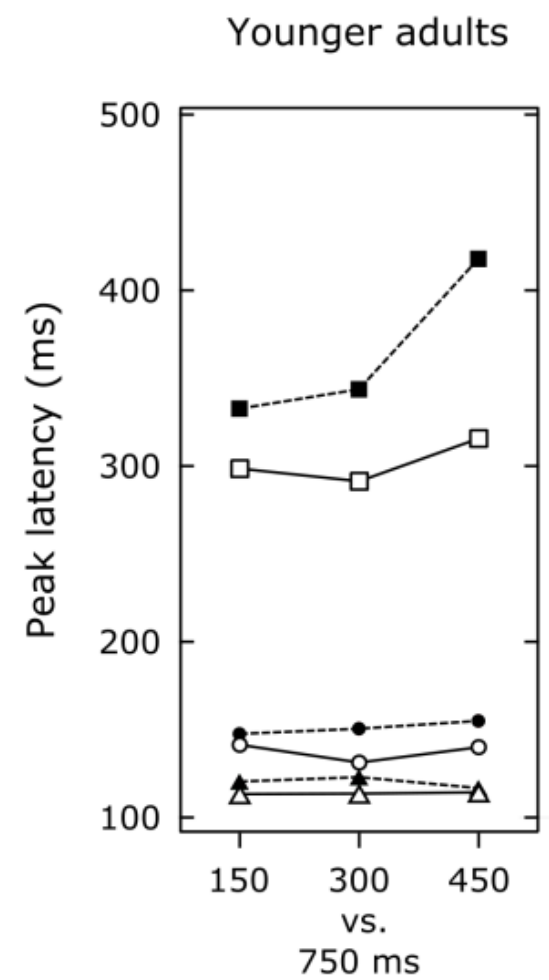

Older adults



Condition

Figure 9. Group-mean jackknife peak latencies for the offset-related P1, N1/N2, and P3b, elicited by short tones in trials with faster-than-, and slower-than-median reaction times in the younger (left) and older adult groups (right), in the three conditions. 